\title{
Interatrial Block Predicts Atrial Fibrillation and Total Mortality in Patients with Cardiac Resynchronization Therapy
}

\author{
Jonatan Jacobsson ${ }^{\mathrm{a}, \mathrm{b}}$ Jonas Carlson ${ }^{\mathrm{a}}$ Christian Reitan ${ }^{\mathrm{a}, \mathrm{c}}$ Rasmus Borgquist ${ }^{\mathrm{a}, \mathrm{d}}$ \\ Pyotr G. Platonov ${ }^{\mathrm{a}}$ \\ a Lund University, Department of Cardiology, Clinical Sciences, Skane University Hospital, Lund, Sweden; \\ ${ }^{b}$ Department of Medicine, Sahlgrenska University Hospital, Mölndal, Sweden; ' Department of Molecular Medicine \\ and Surgery, Karolinska Institute, Solna, Sweden; ${ }^{\mathrm{d} D e p a r t m e n t ~ o f ~ C a r d i o l o g y, ~ A a r h u s ~ U n i v e r s i t y ~ H o s p i t a l, ~ A a r h u s, ~}$ \\ Denmark
}

\section{Keywords}

Heart failure - Atrial fibrillation - Mortality · Risk stratification · Interatrial block - Abnormal P-wave terminal force in lead V1 - Cardiac resynchronization therapy

\begin{abstract}
Background: Interatrial block (IAB) and abnormal P-wave terminal force in lead $\mathrm{V}_{1}\left(\mathrm{PTFV}_{1}\right)$ are electrocardiographic (ECG) abnormalities that have been shown to be associated with new-onset atrial fibrillation (AF) and death. However, their prognostic importance has not been proven in cardiac resynchronization therapy (CRT) recipients. Objective: To assess if IAB and abnormal PTFV 1 are associated with new-onset AF or death in CRT recipients. Methods: CRT recipients with sinus rhythm ECG at CRT implantation and no AF history were included $(n=210)$. Automated analysis of P-wave duration (PWD) and morphology classified patients as having either no IAB (PWD <120 ms), partial IAB (pIAB: PWD $\geq 120 \mathrm{~ms}$, positive $P$ waves in leads II and aVF), or advanced $I A B$ (alAB: PWD $\geq 120 \mathrm{~ms}$ and biphasic or negative $P$ wave in leads II or aVF). PTFV $1>0.04 \mathrm{~mm} \bullet \mathrm{s}$ was considered abnormal. Adjusted Cox regression analyses were performed to assess the impact of IAB and abnormal PTFV 1 on the primary endpoint new-onset $A F$, death, or heart transplant $(\mathrm{HTx})$ and the
\end{abstract}

karger@karger.com www.karger.com/crd

Karger $\frac{1}{\%}$

GOPEN ACCESS
(C) 2020 The Author(s)

Published by S. Karger AG, Basel

This is an Open Access article licensed under the Creative Commons Attribution-NonCommercial-4.0 International License (CC BY-NC) (http://www.karger.com/Services/OpenAccessLicense), applicable to the online version of the article only. Usage and distribution for commercial purposes requires written permission. secondary endpoint death or HTx at 5 years of follow-up. Results: IAB was found in $45 \%$ of all patients and independently predicted the primary endpoint with HR $1.9(95 \% \mathrm{Cl} 1.2-$ $2.9, p=0.004)$ and the secondary endpoint with HR 2.1 (95\% Cl 1.2-3.4, $p=0.006$ ). Abnormal PTFV 1 was not associated with the endpoints. Conclusions: IAB is associated with newonset $A F$ and death in $C R T$ recipients and may be helpful in the risk stratification in the context of heart failure management. Abnormal PTFV 1 did not demonstrate any prognostic value.

(c) 2020 The Author(s)

Published by S. Karger AG, Basel

\section{Introduction}

In general, patients with cardiac resynchronization therapy (CRT) constitute a cohort of patients affected by many comorbidities. CRT significantly reduces morbidity and mortality $[1,2]$; nevertheless, these patients have a relatively short life expectancy [3]. Risk stratification in patients with CRT is difficult and easily available tools for risk stratification are needed.

Interatrial block (IAB) is an electrocardiographic (ECG) sign of an interatrial conduction abnormality de-

Jonatan Jacobsson

Lund University

Avdelningen för Kardiologi

Skånes Universitetssjukhus, SE-221 85 Lund (Sweden)

jonatan.jacobsson@gmail.com 
Fig. 1. Illustration of the IAB groups.

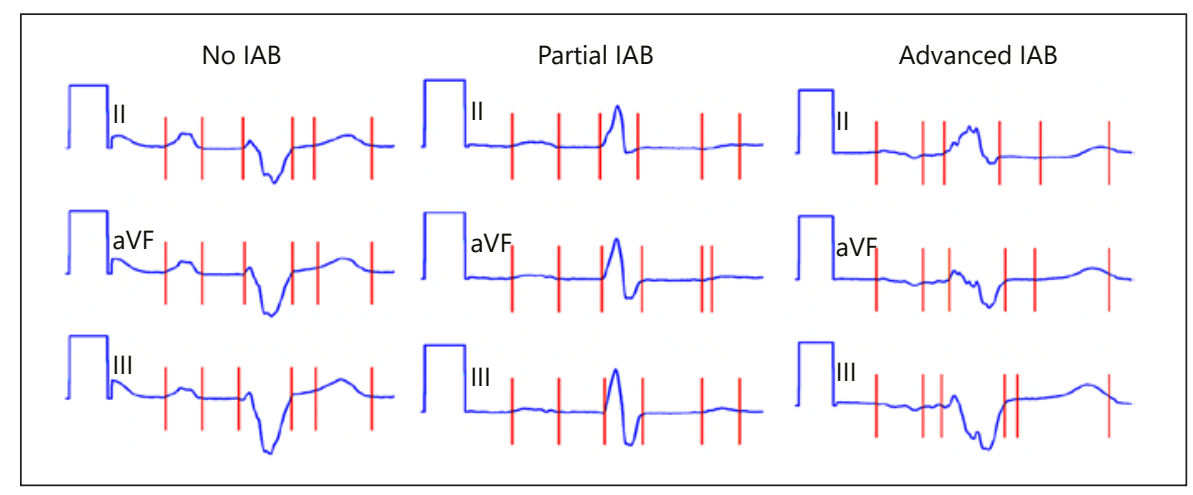

fined as a P-wave duration (PWD) exceeding $120 \mathrm{~ms}$. If, in addition to $\mathrm{P}$-wave prolongation, biphasic $( \pm) \mathrm{P}$ waves are found in inferior leads, it is described as an advanced $\mathrm{IAB}(\mathrm{aIAB})$.

The association of IAB and atrial arrythmias such as atrial fibrillation (AF) is well known [4-8], and the first paper that describes the association of IAB and AF was published by Bayés de Luna et al. [9]. The association was later named Bayes syndrome $[10,11]$. The ability of IAB to predict total mortality is less established, and few studies have assessed the diagnostic value of IAB in patients with severe heart failure (HF). Yet, IAB has been correlated to non-sudden cardiac death in patients with CRT and mild HF [12] and is predictive of total mortality in primary care patients [4]. aIAB is most often found among the most severely ill patients and has been associated with worse outcomes compared to partial IAB (pIAB) based on the data from mixed or relatively healthy cohorts $[4,13]$.

Abnormal P-wave terminal force in lead $\mathrm{V}_{1}\left(\mathrm{PTFV}_{1}\right)$, defined as a terminal negative component of the $\mathrm{P}$ wave of $>0.04 \mathrm{~mm} \bullet \mathrm{s}$ in lead $V_{1}$, is another established ECG abnormality that also has been shown to be predictive of atrial arrhythmias as well as poor outcomes in patients with stroke, in patients with myocardial infarction and in CRT recipients with mild HF and left bundle branch block (LBBB) [14-17].

To our knowledge, the prognostic importance of IAB and abnormal $\mathrm{PTFV}_{1}$ has not been studied in CRT recipients with advanced HF.

\section{Objective}

The main objective of this study was to analyze the prognostic importance of a preprocedural finding of IAB or abnormal $\mathrm{PTFV}_{1}$ in a real-life cohort of CRT recipients. Specifically, we sought to evaluate if IAB and abnor-

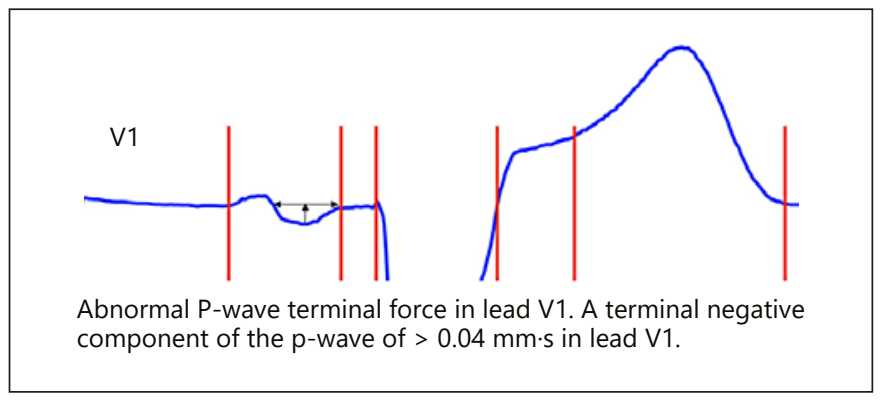

Fig. 2. Illustration of abnormal $\mathrm{PTFV}_{1}$.

mal $\mathrm{PTFV}_{1}$ were associated with a higher risk of newonset AF or death from any cause during follow-up or total mortality alone during follow-up. A secondary objective was to assess if patients with aIAB had an inferior prognosis compared to patients with pIAB.

\section{Methods}

\section{Study Population}

We retrospectively included consecutive patients who received a CRT-pacemaker (CRT-P) or CRT-defibrillator (CRT-D) device between the years 1999 and 2012 in Lund, Skåne, Sweden. All CRT implantations were carried out according to contemporary guidelines [3] and only patients with a successfully implanted CRT-device, an ECG available for analysis with proper signal quality and sinus rhythm (SR) within 180 days from the time of CRT implantation and with no preprocedural history of AF were included. Thus, only patients without any documented AF by the time of CRT implantation were included in the study.

For review, the ECG with the shortest time duration from CRT implantation was evaluated. SR was defined as a positive starting component of the P wave in lead II, and all available ECGs were manually reviewed to validate that the ECG signal quality was ac- 
Table 1. Baseline characteristics of all patients

\begin{tabular}{|c|c|c|c|c|c|}
\hline Parameter & $\begin{array}{l}\text { All patients } \\
(n=210)\end{array}$ & $\begin{array}{l}\text { No IAB } \\
(n=115 ; 55 \%)\end{array}$ & $\begin{array}{l}\text { pIAB } \\
(n=72 ; 34 \%)\end{array}$ & $\begin{array}{l}\text { aIAB } \\
(n=23 ; 11 \%)\end{array}$ & $\begin{array}{l}\text { Any IAB } \\
(n=95 ; 45 \%)\end{array}$ \\
\hline \multicolumn{6}{|l|}{ Demographics } \\
\hline Male, $\%$ & 80 & 76 & $89^{\mathrm{b}}$ & 74 & 85 \\
\hline Ischemic heart disease, $\%$ & 55 & 55 & 58 & 48 & 56 \\
\hline NYHA Class III or IV, \% & 70 & 73 & 65 & 70 & 66 \\
\hline Conventional PM before CRT, \% & 13 & 15 & 13 & 8 & 12 \\
\hline Creatinine, $\mu \mathrm{mol} / \mathrm{L}(\mathrm{IQR})$ & $106(88-134)$ & $106(89-135)$ & $110(85-136)$ & $97(78-106)$ & $106(84-133)$ \\
\hline \multicolumn{6}{|l|}{ Medication at CRT implantation } \\
\hline Beta-blocker, \% & 86 & 83 & 93 & 83 & 91 \\
\hline ACEi or ARB, \% & 96 & 94 & 97 & 100 & 98 \\
\hline Loop diuretic, \% & 92 & 91 & 90 & 100 & 93 \\
\hline QRS duration, ms (SD) & $170(26)$ & $170(25)$ & $168(31)$ & $179(21)$ & $174(28)$ \\
\hline LVEF, \% (IQR) & $25(20-27)$ & $25(20-26)$ & $25(20-30)$ & $25(22-31)$ & $25(20-30)$ \\
\hline $\mathrm{LBBB}, \%$ & 80 & 85 & $72^{\mathrm{b}}$ & 78 & $74^{\mathrm{b}}$ \\
\hline PWD, ms (IQR) & $116(102-130)$ & $104(86-112)$ & $132(125-142)^{\mathrm{b}}$ & $130(126-140)^{\mathrm{b}}$ & $130(126-142)^{\mathrm{b}}$ \\
\hline Abnormal PTFV $_{1}, \%$ & 28 & 17 & $42^{\mathrm{b}}$ & $39^{\mathrm{b}}$ & $41^{\mathrm{b}}$ \\
\hline $\begin{array}{l}\text { Time from analyzed ECG to CRT implant, median (IQR), } \\
\text { days }\end{array}$ & $14(1-58)$ & $15(1-58)$ & $16(1-70)$ & $1(0-49)$ & $12(1-51)$ \\
\hline $\begin{array}{l}\text { Time from first available ECG to CRT implant, median } \\
\text { (IQR), years }\end{array}$ & $10.7(4.6-15.4)$ & $11.6(4.8-16.0)$ & $9.6(4.4-13.5)$ & $11.9(4.3-16.0)$ & $9.7(4.4-13.6)$ \\
\hline $\begin{array}{l}\text { Number of available ECGs before CRT implant, median } \\
\text { (IQR) }\end{array}$ & $20(13-28)$ & $20(13-28)$ & $19(13-29)$ & $19(10-27)$ & $19(12-28)$ \\
\hline \multicolumn{6}{|l|}{ Follow-up characteristics } \\
\hline
\end{tabular}

ceptable and that no patient was included if the ECG showed atrial pacing or AF or if an analysis of the $\mathrm{P}$ wave was not possible. A figure of the full inclusion process is available in online supplementary Figure 1 (see www.karger.com/doi/10.1159/000509916 for all online suppl. material).

\section{Baseline ECG Assessment and Definitions of IAB and} Abnormal PTFV 1

All available preprocedural ECGs as well as ECGs within 180 days after CRT implantation were extracted from the regional electronic database (MUSE Cardiology Information System version 9, GE Healthcare, Chicago, IL, and Infinity Megacare ECG management system, Dräger, Houston, TX, USA) and processed offline. Using the fully automatic Glasgow algorithm [18], an automated analysis of the PWD and the morphology of the P waves in leads $\mathrm{V}_{1}$, II, and aVF was performed. The automatic algorithm allows identification of the $\mathrm{P}$-wave morphology as positive $(+1)$, negative $(-1)$, or biphasic with polarity of the initial deflection defined as positive $(+2)$ or negative $(-2)$.

Patients were classified as having either no IAB (PWD $<120$ $\mathrm{ms}$ ), pIAB (PWD $\geq 120 \mathrm{~ms}$, positive $\mathrm{P}$ waves in leads II and $\mathrm{aVF}$ ) or aIAB (PWD $120 \mathrm{~ms}$ and biphasic [ \pm ] or negative $\mathrm{P}$ waves in leads II or aVF). The definition [13] was established on the notion that aIAB diagnosis should primarily be based on leads II and aVF and that isolated abnormal morphologies in lead III are not sufficiently specific for $\mathrm{aIAB}$ [19]. Illustrations of the different IAB types are found in Figure 1. $\mathrm{PTFV}_{1}>0.04 \mathrm{~mm} \bullet \mathrm{s}$ was considered abnormal [20]. An illustration of an ECG with abnormal PTFV is $_{1}$ found in Figure 2.

\section{Assessment of AF before and after CRT Implantation}

A preprocedural history of AF was evaluated from a manual review of medical records and from the Swedish National Patient Registry (SNPR). The SNPR is administered by the Swedish National Board of Health and Welfare and includes data, starting in the year 1987 on main and secondary diagnoses at discharge from all public hospitals in Sweden. Information about outpatient visits to hospitals is also included. The register uses International Classification of Disease (ICD) codes, with the 9th edition (ICD-9) used between 1987 and 1996, and the 10th edition (ICD-10) used from 1997. AF was defined as the presence of any of the following ICD codes: 427D for ICD-9 and I48 for ICD-10. 
Table 2. Outcome in 5 years of follow-up

\begin{tabular}{lcllll}
\hline Outcome & $\begin{array}{l}\text { All patients } \\
(n=210)\end{array}$ & $\begin{array}{l}\text { No IAB } \\
(n=115 ; 55 \%)\end{array}$ & $\begin{array}{l}\text { pIAB } \\
(n=72 ; 34 \%)\end{array}$ & $\begin{array}{l}\text { aIAB } \\
(n=23 ; 11 \%)\end{array}$ & $\begin{array}{l}\text { Any IAB } \\
(n=95 ; 45 \%)\end{array}$ \\
\hline $\begin{array}{l}\text { Reached primary endpoint } \\
\text { Reached secondary endpoint }\end{array}$ & $105(50)$ & $48(42)$ & $45(63)^{\mathrm{a}}$ & $12(52)$ & $57(60)$ \\
\hline Type of endpoint in 5 years & $75(36)$ & $34(30)$ & $32(44)^{\mathrm{a}}$ & $9(39)$ & $41(43)^{\mathrm{a}}$ \\
$\quad \begin{array}{l}\text { Death } \\
\text { New-onset AF }\end{array}$ & $56(27)$ & $27(24)$ & $23(32)$ & $6(26)$ & $29(31)$ \\
HTx & $46(22)$ & $20(17)$ & $20(28)$ & $6(26)$ & $26(27)$ \\
\end{tabular}

a Significantly different $(p<0.05)$ from no IAB group.

To study if there were any additional AF cases not reflected in the SNPR or medical records, all available digital pre- and postprocedural ECGs were assessed regarding the occurrence of AF. ECGs were obtained from the regional electronic ECG database which contains all ECGs taken in the hospital catchment area, including primary care facilities, starting from the year 1988. If the automated analysis decoded a rhythm on digital ECG as AF, that specific ECG was manually reviewed by a trained physician (J.J.) to evaluate if the automated analysis was appropriate or not. In cases of doubt, a senior cardiologist (P.G.P.) was consulted. If AF was confirmed, the patient was given a diagnosis of AF before or after CRT implantation. If AF was found before CRT implantation, that patient was consequently excluded from the study. Data regarding AF during CRT follow-up was also achieved from the SNPR and the date of the first time when ECG-documented AF was diagnosed at admission to hospital, or at specialized cardiology in- and outpatient visits, was noted.

\section{Study Endpoint}

Information about study endpoints was collected during the period from the time of CRT implantation until September 15, 2017, when data was retrieved from the SNPR. The primary endpoint was a combined endpoint of new-onset AF, death, or heart transplantation (HTx), and the secondary endpoint was death or HTx.

\section{Statistics}

Histograms were used to evaluate if continuous data were normally distributed or not. Non-continuous and continuous variables not normally distributed were reported as median (interquartile range). Continuous, normally distributed variables were reported as mean $\pm \mathrm{SD}$. Baseline clinical characteristics were compared between patients with no IAB and other groups (no IAB vs. pIAB, no IAB vs. $\mathrm{IIAB}$, and no IAB vs. IAB). The $t$ test was used to analyze differences among normally distributed samples, the Mann-Whitney $U$ test to analyze differences among not normally distributed samples, and the Pearson $\chi^{2}$ test to compare categorical variables.

Separate Kaplan-Meier plots with log-rank tests were used to compare 5-year survival with regard to the study endpoints between the groups depending on the presence of IAB and its types and normal versus abnormal $\mathrm{PTFV}_{1}$. Multivariable Cox regression analyses adjusted for age, NYHA class, ischemic HF etiology, left

Interatrial Block Predicts AF and Total

Mortality in CRT Patients ventricular ejection fraction (LVEF), LBBB, and CRT-P versus CRT-D were performed to assess the impact of IAB and abnormal $\mathrm{PTFV}_{1}$ on the risk of primary and secondary endpoints at 5 years after CRT implantation. SPSS Statistics for Macintosh, version 25.0 (IBM Corp., Armonk, NY, USA) was used for all statistical analyses.

\section{Results}

\section{Study Population}

In total, 210 patients were included in the study, and the baseline characteristics of all patients are illustrated in Table 1 . The median age was 67 years, $80 \%$ were male, $70 \%$ had New York Heart Association (NYHA) Class III or IV, $55 \%$ had ischemic etiology of $\mathrm{HF}, 51 \%$ received a CRT-P device, and $80 \%$ had LBBB. Patients with IAB were less likely to have LBBB and more often had abnormal $\mathrm{PTFV}_{1}$, but no other clinically relevant significant differences regarding baseline characteristics were seen when comparing patients with or without IAB. The median time from CRT implantation to the reviewed ECG was 14 days, and the median number of available preprocedural ECGs were 20 per patient, and the median time from the first available ECG to CRT implant was 10.7 years with no significant differences observed between groups. The shortest follow-up time was 4.7 years, and the median follow-up time was 8.4 years with no statistically significant differences observed between the IAB groups.

\section{Clinical Outcome}

In 5 years from CRT implantation, 72 patients (34\%) died, 47 patients (22\%) had new-onset $\mathrm{AF}$, and 3 patients (1\%) underwent HTx. Of the 47 patients with new-onset AF, 16 patients died, and 0 patients were HTx after the AF episode was observed. One patient had new-onset AF after HTx but no patient died after HTx. The outcomes of all patients are found in Table 2 . 


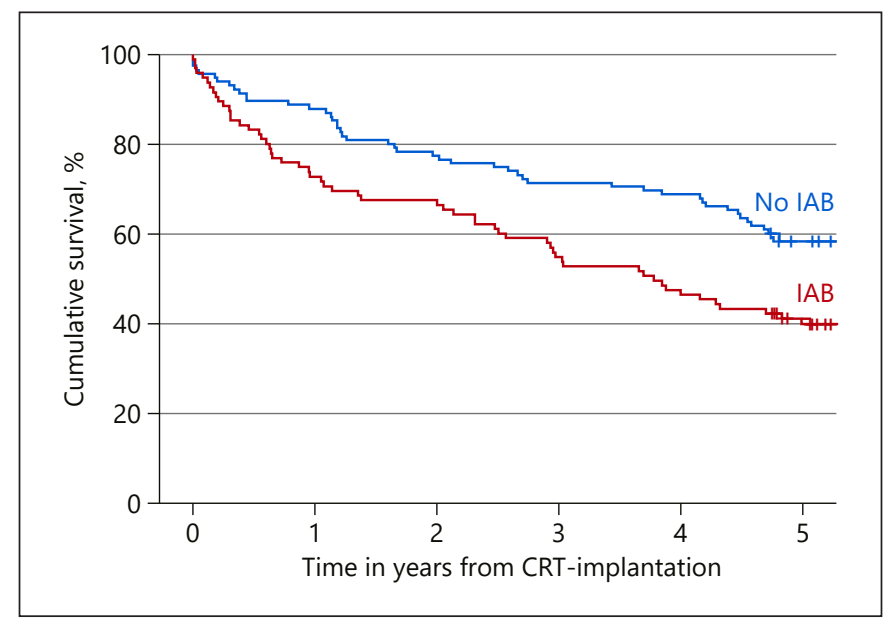

Fig. 3. Kaplan-Meier plot comparing patients with no IAB to patients with IAB. Endpoint: new-onset AF, death, or heart transplant. $\log$-rank $p=0.004$.

\section{Interatrial Block}

In the survival analysis, IAB was associated with a higher risk of the primary endpoint, but patients with aIAB did not have an inferior prognosis compared to patients with pIAB (Fig. 3, 4). IAB was also associated with a higher risk of death from any cause or HTx but aIAB patients did not have an inferior prognosis compared to pIAB patients (see online suppl. Fig. 2 and 3).

In adjusted analysis, IAB was significantly associated with the risk of the primary as well as the secondary endpoint (Table 3). Both pIAB and aIAB were associated with the primary and the secondary endpoints in the univariable and adjusted analyses when compared with the no IAB group (Table 3). No significant outcome differences were observed when comparing patients with pIAB and aIAB (Table 3 ).

\section{Abnormal PTFV}

Abnormal $\mathrm{PTFV}_{1}$ was not associated with any of the endpoints (Fig. 5; Table 3; online suppl. Fig. 4). A forest plot of the adjusted multivariate analysis to the primary and secondary endpoint is presented in Figure 6.

\section{Discussion}

In patients with $\mathrm{HF}$ and $\mathrm{CRT}$, IAB and abnormal $\mathrm{PTFV}_{1}$ are common findings. IAB but not abnormal $\mathrm{PTFV}_{1}$ was associated with the risk of new-onset AF and total mortality independently from other clinical risk factors in our real-life cohort of CRT recipients with severe HF disease. Pa-

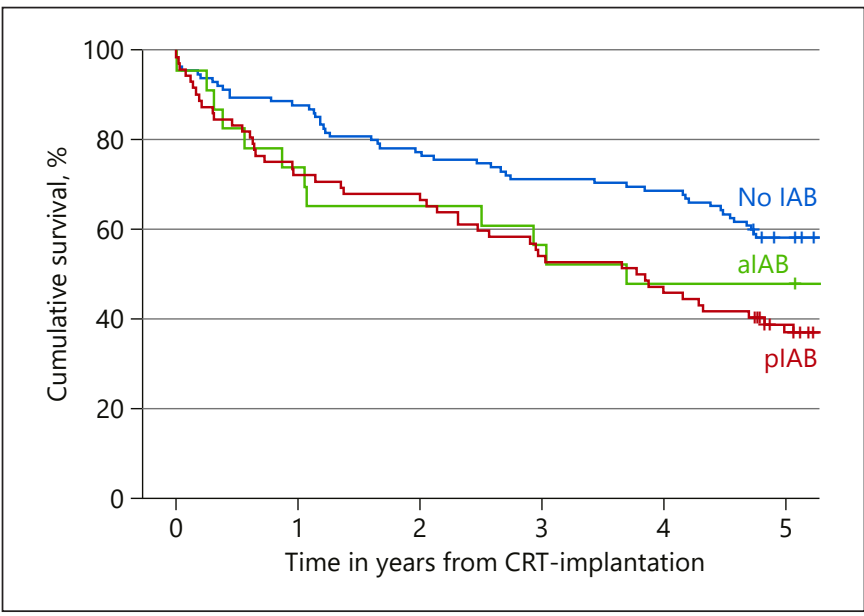

Fig. 4. Kaplan-Meier plot comparing patients with no IAB, to patients with either PIAB or aIAB. Endpoint: new-onset AF, death, or heart transplant. log-rank $p=0.013$.

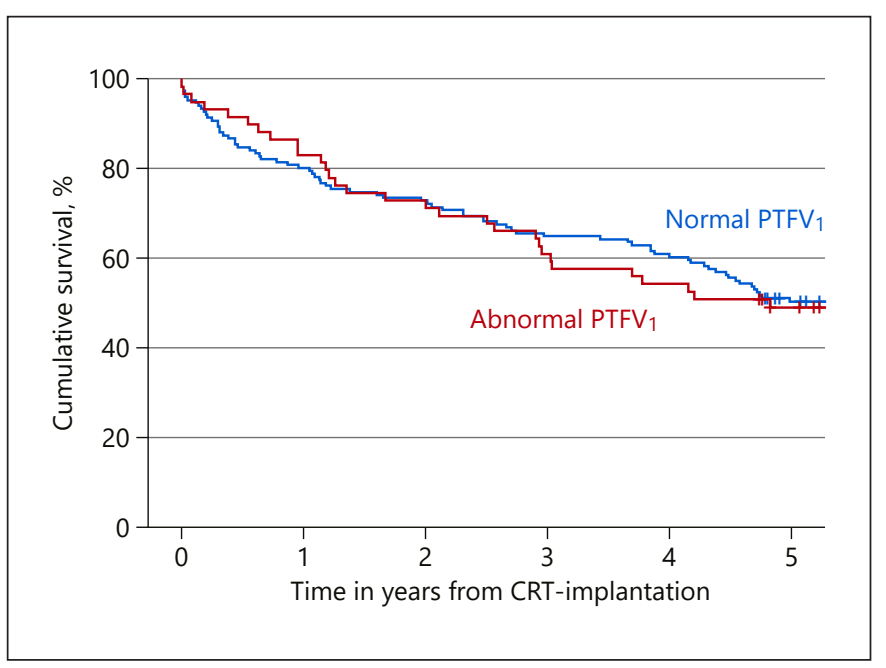

Fig. 5. Kaplan-Meier plot comparing patients with normal $\mathrm{PTFV}_{1}$ to patients with abnormal PTFV ${ }_{1}$. Endpoint: new-onset AF, death, or heart transplant. $\log$-rank $p=0.869$.

tients with aIAB do not seem to have a worse prognosis than patients with $\mathrm{pIAB}$, and the previously recognized doseresponse IAB severity appears to have limited applicable value in patients with advanced severe HF, such as those included in our analysis. We were not able to reproduce previous findings of the association between abnormal $\mathrm{PTFV}_{1}$ and worse outcome. Our results imply that a finding of abnormal $\mathrm{PTFV}_{1}$ may have limited prognostic usefulness in CRT recipients with severe HF. 
Fig. 6. Forest plot of the adjusted multivariate analysis found in Table 3.

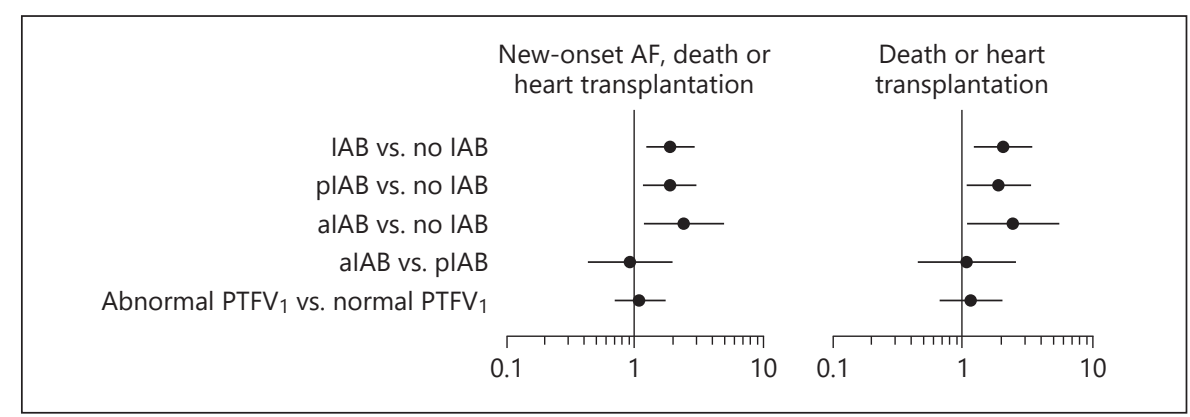

Table 3. Multivariable Cox regression analyses.

\begin{tabular}{|c|c|c|c|c|c|c|}
\hline \multirow[t]{2}{*}{ Parameter } & \multicolumn{3}{|c|}{ Endpoint death/HTx/AF } & \multicolumn{3}{|c|}{ Endpoint death/HTx } \\
\hline & adjusted $\mathrm{HR}^{\mathrm{a}}$ & $95 \% \mathrm{CI}$ & $p$ value & adjusted $\mathrm{HR}^{\mathrm{a}}$ & $95 \% \mathrm{CI}$ & $p$ value \\
\hline IAB vs. no IAB $(n=182)$ & 1.88 & $1.22-2.89$ & 0.004 & 2.05 & $1.23-3.41$ & 0.006 \\
\hline pIAB vs. no IAB $(n=163)$ & 1.86 & $1.16-2.97$ & 0.010 & 1.88 & $1.08-3.27$ & 0.026 \\
\hline aIAB vs. no IAB $(n=122)$ & 2.39 & $1.16-4.92$ & 0.018 & 2.44 & $1.08-5.52$ & 0.032 \\
\hline aIAB vs. pIAB $(n=79)$ & 0.91 & $0.43-1.94$ & 0.804 & 1.07 & $0.45-2.52$ & 0.878 \\
\hline $\begin{array}{l}\text { Abnormal PTFV } 1 \text { vs. } \\
\text { normal PTFV }_{1}(n=182)\end{array}$ & 1.09 & $0.69-1.73$ & 0.707 & 1.16 & $0.67-1.99$ & 0.598 \\
\hline
\end{tabular}

Time from CRT implantation. Follow-up is 5 years. The reference variables are no IAB and normal PTFV $1 .{ }^{a}$ Adjusted for age, NYHA Class, ischemic etiology of HF, LBBB, LVEF, CRT-P vs. CRT-D.

\section{Study Population and Data Availability}

We aimed to study the association between ECG markers of abnormal atrial function with new-onset AF, which requires a reliable identification of patients with preprocedural AF history. Given the paroxysmal nature of the arrhythmia and commonly observed non-specific symptoms, there is always a risk that patients with preexisting AF may have been included as AF-naive. However, we aimed to overcome this by combining screening of multiple preprocedural ECGs along with a meticulous review of medical records cross-linked with the SNPR and therefore believe that our study group represents a reasonable approximation of an AF-free cohort of patients with HF.

In this study, we decided not to include data regarding device-detected episodes of AF as atrial high rate episodes by being surrogate markers of AF may not represent true AF episodes [21-23]. Due to the well-acknowledged uncertainties regarding the clinical meaning of short episodes of device-detected AF [24-27], we believe that newonset AF based only on a ECG-documented clinical AF diagnosis makes the study more robust. Furthermore, as all our patients had regular follow-up through device clinics, patients would receive AF diagnosis code whenever clinical diagnosis of AF was made. Moreover, the
SNPR has been found to be a reliable source of information regarding $\mathrm{AF}$ and was validated previously $[28,29]$, and as a manual review of all available postoperative ECGs added another source of AF, we believe that underdiagnosis of AF was unlikely.

As all included patients received their device according to the guidelines at hand, the population should represent a CRT cohort with advanced HF, and clinicians ought to be able to apply the study's results to most CRT recipients. Thus, we believe that the findings of the study are clinically applicable.

\section{The Prevalence of IAB in Different Populations}

Previous studies reported that the prevalence of IAB is higher among older patients with advanced comorbidities and that it is associated with a more severe underlying heart disease. In hospitalized patients, IAB is common, and several studies have reported an IAB prevalence of over $40 \%$ [30, 31]. Among healthy young men, however, IAB was present in only $9 \%$ of those younger than 35 years and in $5 \%$ of those under 20 years [32]. In patients over 100 years though, IAB was found in $46 \%$ of subjects. $\mathrm{aIAB}$ is far less common than $\mathrm{pIAB}[13,33]$, and the prevalence of $\mathrm{aIAB}$ varies greatly depending on the clinical 
context. It has been reported in around $1 \%$ of patients with mitral valve disease [34], in 14\% of patients undergoing coronary bypass graft surgery [35], in $17 \%$ of patients admitted with HF [36], and in $17 \%$ of ischemic stroke survivors [37].

Prolonged PWD (pIAB) as well as morphological abnormalities in inferior ECG leads (aIAB) are associated with structural abnormalities of the atrial wall such as fibrosis due to ageing and cardiovascular comorbidities [38-40]. One would therefore expect a high prevalence of IAB in CRT recipients. In our study, the prevalence of aIAB (11\%) differed greatly from the findings of Sadiq et al. [6], who reported aIAB prevalence among CRT recipients of as high as $38 \%$. The reasons for this discrepancy are unclear given the fact that Sadiq et al. [6] used a "narrower" definition of aIAB (biphasic morphology of the $\mathrm{P}$ wave in all inferior ECG leads assessed using manual ECG review), while the patient characteristics of their study otherwise were similar to ours.

The methodology of $\mathrm{P}$-wave processing may have contributed to the observed differences in findings. While manual and automatic approaches have their strengths and weaknesses, we have chosen fully automatic P-wave processing in order to eliminate the risk of subjectivity in assessment of PWD and, perhaps more importantly, its morphology and identification of terminal-negative component in the inferior leads and lead V1. As we have shown previously [41], the use of signal amplification may consistently result in longer $\mathrm{PWD}$ values, thus contributing to a greater prevalence of IAB in some studies that used manual measurements $[6,36]$ but not fully explaining the greater prevalence of biphasic $\mathrm{P}$-wave morphology in inferior leads required for $\mathrm{AIAB}$ definition. By adhering to the commercially available automatic ECG processing software, we also aimed to obtain results that can be reproduced by others and applied on a large scale [4].

To summarize, the prevalence of IAB varies significantly in different populations. But, as definitions and assessments of aIAB (e.g., manual reviews of ECG vs. digital analyses) have varied between studies, comparisons and conclusions are difficult to make.

\section{The Prognostic Value of IAB}

CRT recipients represent a cohort with advanced structural heart disease and a high number of comorbidities [3]. Moreover, CRT is a therapy that potentially alters hemodynamics and induces reverse remodeling of the left ventricle with ensuing reduced left atrial pressure [42], so patients with CRT constitute a very special population. Thus, classical predictors of mortality and AF in the general population may not have a similar prognostic value in a subset of patients with HF and CRT. We found that preprocedural IAB could add predictive value to other clinical parameters associated with CRT outcome. Derived from a 12-lead surface ECG, IAB is an easily available non-invasive method that could be helpful in the CRT risk stratification process. A finding of preprocedural IAB should not be ignored, and vigilant monitoring among these patients should be provided as our results indicate that these patients may have a higher risk of death or new-onset AF.

The association of IAB and AF is well known and has been observed in a number of different patient categories [4-7]. Concerning the prognostic influence of IAB in CRT recipients, however, few studies are available. Yet, associations between IAB and new-onset AF have been found before. In the MADIT-CRT cohort, IAB has been found to be predictive of AF $[7,12]$. One should bear in mind though that the MADIT-CRT cohort is represented only by patients in NYHA Class I or II with far less comorbidities compared to our real-life CRT population [42]. Also, the study by Holmqvist et al. [12] used orthogonal ECGs, and the definition of IAB differed therefore from ours. Moreover, the association between IAB and AF has recently been evaluated in CRT recipients by Sadiq et al. [6], who found that $\mathrm{IAB}$ was a predictor of new-onset devicedetected AF. Yet, the incidence of new-onset AF was higher compared to our cohort as $30 \%$ of all patients had AF over a mean follow-up of 32 months. This may be due to the fact that their study included device-detected AF cases, but as it did not include any preprocedural review of ECGs, the number of new-onset AF cases may have been overestimated. However, Sadiq's cohort constituted a real-life CRT population and was not very different from ours, and the relationship between IAB and new-onset AF seems to be true among CRT recipients as well.

To our knowledge, only one study has evaluated the impact of IAB on mortality in CRT recipients. The study by Holmqvist et al. [12] found that IAB on orthogonal ECGs was predictive of non-sudden cardiac death but not allcause mortality in the MADIT-CRT cohort. In the general population, more studies are available. Magnani et al. [43] found that IAB was predictive of cardiovascular and allcause mortality in a representative US sample of patients with mean age of 60 years, and in a recent large Danish study of around 150,000 primary care patients aged 50-90 years, aIAB was found to be predictive of all-cause mortality [4]. The vast number of patients included in the study allowed the authors to find a dose-response relationship between the number of inferior ECG leads with abnormal 
morphology and the outcome. The prevalence of aIAB (defined as at least one inferior lead with biphasic morphology) was noted among $10 \%$ of patients; $7.8,1.6$, and $0.5 \%$ with 1 , 2 , and 3 inferior leads with biphasic morphologies, respectively. All 3 types of aIAB were predictive of AF, but only aIAB with all 3 inferior leads with biphasic morphology was found to be predictive of all-cause mortality. Also, the more inferior leads affected by abnormal P-wave morphologies, the higher were the hazard ratios for AF. In ischemic stroke survivors, aIAB have recently been found to be a predictor of all-cause mortality, but it was an independent predictor only among patients without advanced cardiovascular morbidities (no diabetes, vascular disease, hypertension, or cardiac failure), which supports our observation of diminished prognostic value of ECG markers in patients with advanced disease [37].

The results from the above-mentioned studies along with our findings suggests that IAB have a prognostic value in CRT recipients too, mainly with regard to a higher risk of AF-development. Considering mortality prediction, the value of IAB and especially $\mathrm{aIAB}$ seems to be higher among healthier subjects such as a cohort of primary care patients, in whom aIAB serves as an indicator of more severely affected patients with worse prognosis. In patients with an advanced cardiovascular disease though, other comorbidities probably play a more prominent role resulting in a clinical limited applicability of aIAB P-wave pattern. Yet, our study may have involved too few patients to clearly nuance the previously observed IAB severity differences.

\section{The Prognostic Value of Abnormal PTFV}

We were not able to reproduce previous findings regarding the correlation between abnormal $\mathrm{PTFV}_{1}$ and worse outcomes [14-16]. In our study, $\mathrm{PTFV}_{1}$ did not correlate with the endpoints in patients with LBBB either (see online suppl. Fig. 5, 6), as in Baturova's study of MADIT-CRT patients [17]. Baturova's cohort was very different from ours with younger patients in NYHA Class I or II, and the conflicting results may be explained by the obvious differences between the 2 populations. Alternatively, our study may have been underpowered to find any prognostic significance of abnormal $\mathrm{PTFV}_{1}$. However, given the lack of survival difference between patients with and without abnormal $\mathrm{PTFV}_{1}$, it is unlikely that the abnormal $\mathrm{PTFV}_{1}$ bears clinically significant meaning with regard to prognosis for patients with severe HF treated with CRT, and from our findings it seems as if abnormal $\mathrm{PTFV}_{1}$ has limited applicable value in this very sick population in line with previous studies that have shown limitations of abnormal $\mathrm{PTFV}_{1}$ in different study popula- tions $[44,45]$. Our results need to be confirmed in future studies before any conclusions can be made.

\section{Strengths and Limitations}

Our study included patients with CRT and available preprocedural medical history. A long-term follow-up was available, and no patient was lost to follow-up during the 5-year follow-up period. All devices were implanted according to current ESC CRT guidelines at the time of CRT implantation, and thus our cohort represents a reallife CRT population. All patients had an available ECG within reasonable time from CRT implantation. We believe that a great majority of AF during follow-up represents new-onset AF partly because we used a number of different reliable sources to collect data regarding preprocedural AF history. During follow-up, we may have missed some cases of new-onset AF as no device-detected data regarding AF was included in the study. The study included a limited number of patients, and only a few more events, especially in the aIAB group, potentially could change the results significantly.

\section{Conclusions}

$\mathrm{IAB}$ is an independent predictor of new-onset $\mathrm{AF}$ and death in CRT recipients with severe HF. As a non-invasive, easily available method, IAB adds prognostic value and may be helpful in risk stratification in the context of $\mathrm{HF}$ management. Abnormal $\mathrm{PTFV}_{1}$ did not demonstrate any prognostic value in patients with advanced HF disease.

\section{Statement of Ethics}

The study was approved by the local Ethics Committee.

\section{Conflict of Interest Statement}

R.B. received lecture fees from Medtronic and Abbot. The other authors declare that they have no conflicts of interest or financial ties to disclose.

\section{Funding Sources}

Governmental funding of clinical research within the Swedish National Health Service (ALF), grants from The Swedish HeartLung Foundation, and donation funds at Skane University Hospital supported this study. The funders had no role in study design, data collection and analysis, decision to publish, or preparation of the manuscript. 


\section{References}

1 Cleland JG, Daubert JC, Erdmann E, Freemantle N, Gras D, Kappenberger L, et al.; Cardiac Resynchronization-Heart Failure (CARE-HF) Study Investigators. The effect of cardiac resynchronization on morbidity and mortality in heart failure. N Engl J Med. 2005 Apr;352(15):1539-49.

2 Bristow MR, Saxon LA, Boehmer J, Krueger S, Kass DA, De Marco T, et al.; Comparison of Medical Therapy, Pacing, and Defibrillation in Heart Failure (COMPANION) Investigators. Cardiac-resynchronization therapy with or without an implantable defibrillator in advanced chronic heart failure. N Engl J Med. 2004 May;350(21):2140-50.

3 Brignole M, Auricchio A, Baron-Esquivias G, Bordachar P, Boriani G, Breithardt OA, et al.; Document Reviewers. 2013 ESC Guidelines on cardiac pacing and cardiac resynchronization therapy: the Task Force on cardiac pacing and resynchronization therapy of the European Society of Cardiology (ESC). Developed in collaboration with the European Heart Rhythm Association (EHRA). Eur Heart J. 2013 Aug;34(29):2281-329.

4 Skov MW, Ghouse J, Kühl JT, Platonov PG, Graff C, Fuchs A, et al. Risk Prediction of Atrial Fibrillation Based on Electrocardiographic Interatrial Block. J Am Heart Assoc. 2018 May;7(11):7.

5 O’Neal WT, Zhang ZM, Loehr LR, Chen LY, Alonso A, Soliman EZ. Electrocardiographic Advanced Interatrial Block and Atrial Fibrillation Risk in the General Population. Am J Cardiol. 2016 Jun;117(11):1755-9.

6 Sadiq Ali F, Enriquez A, Conde D, Redfearn D, Michael K, Simpson C, et al. Advanced Interatrial Block Predicts New Onset Atrial Fibrillation in Patients with Severe Heart Failure and Cardiac Resynchronization Therapy. Ann Noninvasive Electrocardiol. 2015 Nov; 20(6):586-91.

7 Holmqvist F, Platonov PG, Carlson J, Zareba W, Moss AJ; MADIT II Investigators. Altered interatrial conduction detected in MADIT II patients bound to develop atrial fibrillation. Ann Noninvasive Electrocardiol. 2009 Jul; 14(3):268-75.

8 Escobar-Robledo LA, Bayés-de-Luna A, Lupón J, Baranchuk A, Moliner P, MartínezSellés M, et al. Advanced interatrial block predicts new-onset atrial fibrillation and ischemic stroke in patients with heart failure: The “Bayes' Syndrome-HF” study. Int J Cardiol. 2018 Nov;271:174-80.

9 Bayés de Luna A, Cladellas M, Oter R, Torner P, Guindo J, Martí V, et al. Interatrial conduction block and retrograde activation of the left atrium and paroxysmal supraventricular tachyarrhythmia. Eur Heart J. 1988 Oct;9(10): 1112-8.

10 Conde D, Baranchuk A. [Interatrial block as anatomical-electrical substrate for supraventricular arrhythmias: bayés syndrome]. Arch Cardiol Mex. 2014 Jan-Mar;84(1):32-40.
11 Bacharova L, Wagner GS. The time for naming the Interatrial Block Syndrome: bayes Syndrome. J Electrocardiol. 2015 Mar-Apr; 48(2):133-4.

12 Holmqvist F, Platonov PG, McNitt S, Polonsky S, Carlson J, Zareba W, et al.; MADIT II Investigators. Abnormal P-wave morphology is a predictor of atrial fibrillation development and cardiac death in MADIT II patients. Ann Noninvasive Electrocardiol. 2010 Jan; 15(1):63-72.

13 Bayés de Luna A, Platonov P, Cosio FG, Cygankiewicz I, Pastore C, Baranowski $\mathrm{R}$, et al. Interatrial blocks. A separate entity from left atrial enlargement: a consensus report. J Electrocardiol. 2012 Sep;45(5):445-51.

14 Liu G, Tamura A, Torigoe K, Kawano Y, Shinozaki K, Kotoku M, et al. Abnormal P-wave terminal force in lead V1 is associated with cardiac death or hospitalization for heart failure in prior myocardial infarction. Heart Vessels. 2013 Nov;28(6):690-5.

15 Li Q, Gu LD, Zhang C, Liu W, Peng Y, Chai $\mathrm{H}$, et al. A Predictive Study of the Dynamic Development of the P-Wave Terminal Force in Lead V1 in the Electrocardiogram in Relation to Long-Term Prognosis in Non-ST-Segment Elevation Acute Coronary Syndrome Patients during Hospitalization. Ann Noninvasive Electrocardiol. 2015 Nov;20(6):54253.

16 Goda T, Sugiyama Y, Ohara N, et al. P-Wave Terminal Force in Lead V1 Predicts Paroxysmal Atrial Fibrillation in Acute Ischemic Stroke. J Stroke Cerebrovasc Dis. 2017 Sep; 26(9):1912-5.

17 Baturova MA, Kutyifa V, McNitt S, Polonsky B, Solomon S, Carlson J, et al. Usefulness of Electrocardiographic Left Atrial Abnormality to Predict Response to Cardiac Resynchronization Therapy in Patients With Mild Heart Failure and Left Bundle Branch Block (a Multicenter Automatic Defibrillator Implantation Trial with Cardiac Resynchronization Therapy Substudy). Am J Cardiol. 2018 Jul; 122(2):268-74.

18 Macfarlane PW, Devine B, Clark E. The University of Glasgow (Uni-G) ECG analysis program. Comput Cardiol. 2005;32:451-4.

19 Bayés de Luna A, Escobar-Robledo LA, Aristizabal D, Weir Restrepo D, Mendieta G, Massó van Roessel A, et al. Atypical advanced interatrial blocks: definition and electrocardiographic recognition. J Electrocardiol. 2018 Nov - Dec;51(6):1091-3.

20 Morris JJ Jr, Estes EH Jr, Whalen RE, Thompson HK Jr, McIntosh HD. P-Wave Analysis in Valvular Heart Disease. Circulation. 1964 Feb;29(2):242-52.

21 Purerfellner H, Gillis AM, Holbrook R, Hettrick DA. Accuracy of atrial tachyarrhythmia detection in implantable devices with arrhythmia therapies. Pacing Clin Electrophysiol. 2004 Jul;27(7):983-92.
22 Passman RS, Weinberg KM, Freher M, Denes P, Schaechter A, Goldberger JJ, et al. Accuracy of mode switch algorithms for detection of atrial tachyarrhythmias. J Cardiovasc Electrophysiol. 2004 Jul;15(7):773-7.

23 Jedrzejczyk-Patej E, Lenarczyk R, Mazurek $\mathrm{M}$, et al. Can we rely on machines? Devicedetected atrial high rates correspond well with atrial arrhythmias in cardiac resynchronization recipients. Europace. 2016 Mar;18(3): 436-44.

24 Healey JS, Connolly SJ, Gold MR, Israel CW, Van Gelder IC, Capucci A, et al.; ASSERT Investigators. Subclinical atrial fibrillation and the risk of stroke. N Engl J Med. 2012 Jan; 366(2):120-9.

25 Swiryn S, Orlov MV, Benditt DG, DiMarco JP, Lloyd-Jones DM, Karst E, et al.; RATE Registry Investigators. Clinical Implications of Brief Device-Detected Atrial Tachyarrhythmias in a Cardiac Rhythm Management Device Population: Results from the Registry of Atrial Tachycardia and Atrial Fibrillation Episodes. Circulation. 2016 Oct;134(16): 1130-40.

26 Jacobsson J, Reitan C, Carlson J, Borgquist R, Platonov PG. Atrial fibrillation incidence and impact of biventricular pacing on long-term outcome in patients with heart failure treated with cardiac resynchronization therapy. BMC Cardiovasc Disord. 2019 Aug; 19(1):195.

27 Witt CT, Kronborg MB, Nohr EA, Mortensen PT, Gerdes C, Nielsen JC. Early detection of atrial high rate episodes predicts atrial fibrillation and thromboembolic events in patients with cardiac resynchronization therapy. Heart Rhythm. 2015 Dec; 12(12):2368-75.

28 Smith JG, Platonov PG, Hedblad B, Engström G, Melander O. Atrial fibrillation in the Malmö Diet and Cancer study: a study of occurrence, risk factors and diagnostic validity. Eur J Epidemiol. 2010 Feb;25(2):95-102.

29 Baturova MA, Lindgren A, Carlson J, Shubik YV, Bertil Olsson S, Platonov PG. Atrial fibrillation in patients with ischaemic stroke in the Swedish national patient registers: how much do we miss? Europace. 2014 Dec; 16(12):1714-9.

30 Jairath UC, Spodick DH. Exceptional prevalence of interatrial block in a general hospital population. Clin Cardiol. 2001 Aug;24(8): 548-50.

31 Asad N, Spodick DH. Prevalence of interatrial block in a general hospital population. Am J Cardiol. 2003 Mar;91(5):609-10.

32 Gialafos E, Psaltopoulou T, Papaioannou TG, Synetos A, Dilaveris P, Andrikopoulos G, et al. Prevalence of interatrial block in young healthy men $[\{\mathrm{LT}\}] 35$ years of age. Am J Cardiol. 2007 Sep;100(6):995-7.

33 Kitkungvan D, Spodick DH. Interatrial block: is it time for more attention? J Electrocardiol. 2009 Nov-Dec;42(6):687-92. 
34 Bayes de Luna A, Fort de Ribot R, Trilla E, Julia J, Garcia J, Sadurni J, et al. Electrocardiographic and vectorcardiographic study of interatrial conduction disturbances with left atrial retrograde activation. J Electrocardiol. 1985 Jan;18(1):1-13.

35 Conde D, van Oosten EM, Hamilton A, Petsikas D, Payne D, Redfearn DP, et al. Prevalence of interatrial block in patients undergoing coronary bypass graft surgery. Int J Cardiol. 2014 Feb;171(3):e98-9.

36 Martínez-Sellés M. Prevalence and incidence of interatrial block in global population and in different clinical situations. J Geriatr Cardiol. 2017 Mar;14(3):158-60.

37 Baturova MA, Lindgren A, Shubik YV, Carlson J, Platonov PG. Interatrial block in prediction of all-cause mortality after first-ever ischemic stroke. BMC Cardiovasc Disord. 2019 Feb;19(1):37.
38 Bernal E, Bayés-Genís A, Ariza-Solé A, Formiga F, Vidán MT, Escobar-Robledo LA, et al. Interatrial block, frailty and prognosis in elderly patients with myocardial infarction. J Electrocardiol. 2018 Jan - Feb;51(1):1-7.

39 Platonov PG. Interatrial conduction in the mechanisms of atrial fibrillation: from anatomy to cardiac signals and new treatment modalities. Europace. 2007 Nov;9 Suppl 6:vi106.

40 Huo Y, Mitrofanova L, Orshanskaya V, Holmberg P, Holmqvist F, Platonov PG. Pwave characteristics and histological atrial abnormality. J Electrocardiol. 2014 May-Jun; 47(3):275-80

41 Holmqvist F, Platonov PG, Havmöller R, Carlson J. Signal-averaged $\mathrm{P}$ wave analysis for delineation of interatrial conduction - further validation of the method. BMC Cardiovasc Disord. 2007 Oct;7(1):29.
42 Moss AJ, Hall WJ, Cannom DS, Klein $\mathrm{H}$ Brown MW, Daubert JP, et al.; MADIT-CRT Trial Investigators. Cardiac-resynchronization therapy for the prevention of heart-failure events. N Engl J Med. 2009 Oct;361(14): 1329-38.

43 Magnani JW, Gorodeski EZ, Johnson VM, et al. $\mathrm{P}$ wave duration is associated with cardiovascular and all-cause mortality outcomes: the National Health and Nutrition Examination Survey. Heart Rhythm. 2011 Jan;8(1): 93-100.

44 Sajeev JK, Koshy AN, Dewey H, Kalman JM, Bhatia M, Roberts L, et al. Poor reliability of $\mathrm{P}$-wave terminal force $\mathrm{V} 1$ in ischemic stroke. J Electrocardiol. 2019 Jan - Feb;52:47-52.

45 Huang Z, Zheng Z, Wu B, Tang L, Xie X, Dong $R$, et al. Predictive value of $P$ wave terminal force in lead V1 for atrial fibrillation: A meta-analysis. Ann Noninvasive Electrocardiol. 2020 Jul;25(4):e12739. 